Welch, G.F., Ockelford, A., Carter, F-C., Zimmermann, S-A., \& Himonides, E. (2009). 'Sounds of Intent': Mapping musical behaviour and development in children and young people with complex needs. Psychology of Music, 37(3), 348370.

\title{
'Sounds of Intent': Mapping Musical Development in Children and Young People with Complex
}

\author{
Needs
}

\section{Introduction and context}

This article reports on the conceptualisation and initial fieldwork outcomes of a study that was designed to explore the nature of musical development in children and young people with complex needs. ${ }^{1}$ A position paper by Ockelford (2000) suggested that music in the education of such pupils should be recognised as having two distinct strands: music 'in its own right' (to promote musical skills, knowledge and understanding) and music 'to promote wider learning and development' (such as fostering social and communication skills and improving motor control). With regard to the first strand in particular, research was relatively rare. Generally, those with disabilities (whether complex or otherwise) are relatively under-represented in the music education and music psychology research literatures (Jellison, 2000), notwithstanding the many studies in the field of music therapy - the latter being defined as 'the functional use of music to reach non-musical objectives' (Jellison, 2006a, p. 236).

\footnotetext{
${ }^{1}$ The term 'complex needs' has a variety of meanings in the field of special education. Rankin and Regan (2004) suggest that the label implies both (i) breadth - multiple needs (more than one) that are interrelated or interconnected and (ii) depth profound, severe, serious or intense needs (cited by Rosengard et al, 2007: 6). In the current article, the term is used specifically to refer to children and young people with severe learning difficulties ('SLD') or profound and multiple difficulties ('PMLD'), who, in global terms, are functioning as in the first 30 months of 'typical' development (see Welch, Ockelford and Zimmermann, 2001; Ockelford, 2008). There are thought to be approximately 32,000 pupils with SLD and 9,000 pupils with PMLD in the special school sector in England (DfES/ONS, 2005; House of Commons, 2006). The 'MENCAP' website defines PMLD as 'people with more than one disability; have a profound learning disability; have great difficulty communicating; need high levels of support with most aspects of daily life; may have additional sensory or physical difficulties, complex health needs or mental health difficulties; may have behaviours that challenge us'. (Retrieved 13 September 2007 from http://www.mencap.org.uk/html/campaigns/PMLD/pmld definition.asp).
} 
Where comparative research data exist between able-bodied children and those with disabilities (reported, for example, by Cassidy, 1992; Darrow, 1984; Flowers \& Wang, 2002; Stordahl, 2002; Swedberg, 2007), the evidence suggests that disabled children do indeed demonstrate a range of musical capabilities. Similarly, studies with disabled adults have reported the benefits of sustained musical activity in the improvement of specific musical skills ( $c f$ MacDonald et al, 1999; O'Donnell et al, 1999). Nevertheless, until now, musical behaviour has not been systematically investigated in children and young people with complex needs ${ }^{2}$.

The research reported here was preceded by an initial survey of the provision of music in special schools in England (known subsequently as the PROMISE report - Welch, Ockelford and Zimmermann, 2001; Ockelford, Welch and Zimmermann, 2002)3. This survey was designed to map the extent to which the special school sector incorporated music into the daily lives of their pupils. The schools' data from the PROMISE survey suggested that significant non-musical benefits had been noted by teachers and parents as one of the outcomes of their children's participation in musical activity (Ockelford et al., op.cit.). These included reports of heightened interpersonal communication skills, more focused, attentive behaviour, and intensified social participation. In addition, respondents commented that a significant minority (1:10) of pupils demonstrated a flair for, or a particular interest in, music; if extrapolated to the complex needs population in schools, this equates to approximately 4,000 pupils. Overall, all the head teachers in the survey were very positive about the benefits of musical activities, both for musical development and also to assist other forms of development.

Recent analysis of special school inspection reports from the Office for Standards in Education (OfSTED) confirms that inspectors similarly report non-musical benefits from musical activities (Ockelford, 2008). Nevertheless, in terms of education in music (as opposed to education through

\footnotetext{
${ }^{2}$ Similarly, a review of thirty years of research by Jellison \& Taylor (2007) into attitudes towards inclusion reported that they could find only two studies where children with disabilities were participants.

${ }^{3}$ Funded by the Esmée Fairbairn Foundation, with support from the Royal National Institute of Blind People (RNIB).

${ }^{4} \mathrm{~A}$ recent survey by some members of the research team has also revealed the significance of music in the presence of complex needs, in this case through an investigation of blind and partially-sighted children and young people with septooptic dysplasia (Ockelford, Pring, Welch \& Treffert, 2006).
} 
music), although head teachers and others were generally extremely positive about the benefits of their pupils engaging in music activities, until recently that has been no nationally agreed music curriculum in England for children functioning below Level 1 of the National Curriculum (the entry baseline in the design of the National Curriculum for music). As a result, little or no distinction has been made between musical attainment and progress in the context of complex needs (Ockelford, 2000; Welch et al, op.cit.). The situation continues, notwithstanding the publication by the UK Government's Qualifications and Curriculum Authority (QCA, 2001) of 'Planning, teaching and assessing the curriculum for pupils with learning difficulties' - the so-called 'P-Levels' for music as they are known in the special education sector. Analyses of this document by Ockelford, Zimmermann \& Welch (2002) and Ockelford (2008) revealed serious weaknesses in the conceptualisation of the performance descriptions that were set out.

The first difficulty was the basis on which the P-Levels were developed: although they are said to 'draw on effective practice across a range of schools', it remains unclear what evidence was used to underpin their construction. In the absence of a demonstrable, empirical foundation, the reader (practitioner or researcher) is left with an abiding sense of the anecdotal. In relation to music, for example, the following is an exhaustive list of the examples given for the first three official levels (P1 to $\mathrm{P} 3)^{5}$

- $\quad$ startles at sudden noise [P1, (i)];

- $\quad$ becomes still in a concert hall [P1, (ii)];

- becomes excited at repeated patterns of sounds [P1, (ii)];

- $\quad$ turns towards unfamiliar sounds [P2, (i)];

- looks for the source of music [P2, (i)];

- $\quad$ is encouraged to stroke the strings of a guitar [P2, (i)];

${ }^{5}$ Some examples, which do not in reality pertain to achievement in music (such as 'leading an adult to the CD player'), are omitted. 
- relaxes during certain pieces of music but not others [P2, (ii)];

- recognizes a favourite song [P2, (ii)];

- repeatedly presses the keys of an electronic keyboard instrument [P2, (ii)];

- taps piano keys gently and with more vigour [P2, (ii)];

- listens intently when moving across and through a sound beam [P3, (i)];

- anticipates a loud sound at a particular point in a piece of music [P3, (ii)];

- taps, strokes, rubs or shakes an instrument to produce various effects [P3, (ii)].

One wonders how these examples could possibly be thought to be representative when there is no mention (for example) of vocalization or vocal interaction - widely considered to be the bedrock of early music-making and musical communication (see, for instance, H. Papoušek, 1996, p.58; Trevarthen, 2002; Welch 2005) and widely reported by teacher respondents in the earlier PROMISE survey (Welch et al, 2001) as a sign of pupils' musical engagement.

Conceptually, the P-Levels suffer also from the major disadvantage of starting with what is essentially an arbitrary cultural construct (the division of children's learning into curriculum subject areas) and working 'backwards' to the earliest stages of development. Inevitably, there is a fault line where children's personal evolutionary paths coming 'forwards' meet the tracks of the National Curriculum extrapolated 'backwards' - a discontinuity that seems to be recognized implicitly with the move to subject-focused descriptors at P-Level 4. But is this, in any case, the appropriate tack to take? It relies on at least two assumptions: first, that a pupil with PMLD (the most extreme subcategorisation of complex needs) who is functioning globally at a 'typical' 12-month developmental level (with all the challenges inherent in how this working definition of PMLD might be made explicit) is ready to learn in discrete subject areas; and second, that this state of readiness occurs at the same point in different educational domains. 
This analysis begs a number of questions. For example, at what stage does music become a distinct strand in human thinking? Although the answer is not straightforward, the available research evidence concerning 'normal' development in infancy suggests that there is a universal predisposition to musical behaviour: 'It is clear that infants do not begin life with a blank musical slate' (Trehub, 2003, p.13). Consequently, this has been taken as the default position underpinning our investigation, namely that it may be possible to uncover musical behaviours in the context of complex needs if the researchers are open and sensitive to this possibility. For instance, it appears that, even before birth, the developing foetus can become aware of certain pieces or passages of music, as well as the tone of their mother's voice and the language that she speaks ( $c f$ Parncutt, 2006). To all or any of these classes of sound, the unborn child may develop a particular sensitivity, which may subsequently influence his or her auditory preferences post partum (Lecanuet, 1996; Parncutt, op.cit.; Welch, 2005). Hence it may be that among those pupils with even the most profound learning difficulties, there are some who will be responsive to particular pieces of music, suggesting the presence of some form of discrete cognitive processing. Then, according to Trehub (1990), by the age of five or six months, infants can discriminate between different melodic patterns according to the ways in which the notes relate to one another - detecting violations in contour while appreciating the isomorphic nature of transposition, for example. The infant's representation of melodies is abstract, with contour playing a critical role (Trehub, 2006). At this stage, babies integrate repetition and variety into their vocal production, showing 'persistent motivation to reproduce sounds discovered by chance, and to repeat and modify their vocal products with overt signs of effort, eagerness, and joy’ (M. Papoušek, 1996, pp. 104 and 105.) Later, from seven to 11 months, the notion of repeating and varying groups of sounds as the basic units of proto-musical structure appears: 'canonical babbling involves production of regular-beat rhythms with superimposed melodies, short musical patterns or phrases that soon become the core units for a new level of vocal practising and play' (M. Papoušek, op. cit, p. 106). Again, if applied to a 
special needs context, the implication is that pupils with PMLD may be able to process and produce certain forms of musical structure.

In other respects, though, the development of musical perception and thinking appears to be inextricably intertwined with that in other domains - particularly verbal language. For example, M. Papoušek (1996, p. 90) notes that "from early on, parents and infants share a "prelinguistic alphabet" or code in the form of musical elements that both infant-directed speech and infant vocal sounds have in common'. So, preverbal communication 'may represent a common ontogenetic avenue along with two highly structured and exclusively human capacities develop: speech and singing' (op. cit., p. 104). Similarly, Fassbender (1996, p. 80) observes that, to begin with, "perceptions of speech and music seem to arise from the same basis, but they may take different developmental courses when meaning becomes attached to specific acoustical information in the social interaction of intuitive parenting'. And this early connection between language and music apparently has longer-term developmental consequences since, according to M. Papoušek (op. cit., p. 90), the 'proportion of reciprocal vocal matching and maternal imitation during mother-infant interactions before 6 months of age predicts the rate of infant lexical imitation at 15 months of age'. This suggests that teachers and therapists working with those with profound developmental delay, as well as valuing pupils' vocal communication as a natural and valid form of expression in its own right, should also conceptualize it as a precursor both to speech and to singing (see also Molino, 2000; Welch, 2005).

This, then, is one of the broader issues concerning the P-Levels for music. However, their content also raises a number of specific concerns. These are best illustrated by allocating the material presented in the Performance Descriptions to one of three domains: 'listening, reacting and responding', 'causing, creating and controlling (alone or with others)', and 'reflecting on / communicating about music', which represent a simplification and consolidation of the four aspects of music identified in the National Curriculum for Music in England Programmes of Study ('Listening, and applying knowledge and understanding', 'Controlling sounds through singing and playing - 
performing skills', 'Creating and developing musical ideas - composing skills', and 'Responding and reviewing - appraising skills'). Here, the analysis is restricted to Levels P1-P3 (corresponding to the curriculum for complex needs pupils with PMLD) (see Table 1).

\section{INSERT TABLE 1 ABOUT HERE}

Table 1: An analysis of formal 'Performance Descriptions' (as published by the UK Qualifications and Curriculum Authority - QCA) in relation to three domains of musical engagement

Re-casting the Performance Descriptions for music in this format reveals a number of problems with their structure and content. First, and most obviously, there are gaps. There is nothing mentioned in relation to causing, creating or controlling sounds at P1(ii), for example - at a time when pupils are apparently showing an 'emerging awareness of activities and experiences'. Second, the descriptors are often ambiguous. For example, P3(i) states, 'They participate in shared activities with less support'. Less than what? What kind of support? As a result, it is sometimes unclear how levels are meant to be distinguished from one another. For example, at Level P3(i), 'They remember responses over more extended periods', while at P3(ii), 'They can remember learned responses over increasing periods'. How could teachers reasonably be expected to evaluate pupils' attainment using non-specific criteria such as these?

Sometimes, problems appear to arise because of the difficulty in trying make music conform to the general developmental path that Levels P1-P3 seek to map out. For example, at P3(ii), 'They apply potential solutions systematically to problems, for example, indicating by eye contact or gesture the pupil whose turn it is to play in a 'call and response' activity. Moreover, the example given here only tenuously pertains to attainment in music. Others have nothing to do with music at all - for example, P3(ii), 'They greet known people'. 
Some of these problems have been acknowledged by the QCA themselves in subsequent discussions with the research team and the QCA have indicated that they would welcome input into a reformulation of what might be expected for the complex needs (SLD/PMLD) population.

Consequently, the Sounds of Intent project has been designed to critique, refine and extend an original framework of musical development for children with complex needs, specifically for those with profound and multiple learning difficulties (PMLD). The intention is that this framework could be used to inform and underpin the construction and implementation of effective music intervention strategies in schools and to enhance the capacity of the mainstream sector to include children with complex needs in the early years.

\section{The 'Sounds of Intent' Project}

In order to begin to understand the nature of musical behaviour and development in children and young people with complex needs, a working group was created that expanded the original PROMISE research team with practitioners who were active in the field, including music therapists, teachers (music specialists and non-specialists), and graduate researchers. The initial focus was on developing accurate descriptions and shared interpretations of musical behaviour that were grounded in the group's observation of individual case study behaviours ( $c f$ Dey 2007, p. 188 - 'Categories are inherently theoretical, implicitly explanatory, and often metaphorical and exemplary rather than rule bound'). With the appropriate ethical approvals, members of the group held half-day meetings either once or twice per term over a two year period to analyse in detail video recordings of individual children and young people with complex needs engaging (or apparently failing to engage) in musical activity. The children's responses, actions and interactions were carefully noted, and attempts were made to gauge which of these could reasonably be considered to be indicative of musical attainment or progress. A number of short, field-based examples follow. 


\section{Observations}

1. A sits motionless in her chair. Her teacher approaches and plays a cymbal with a soft beater, gently at first, and then more loudly, in front of her and then near to each ear. A does not appear to react.

2. R is lying in the 'Little Room', ${ }^{6}$ vocalizing in an almost constant drone. Occasionally a sudden movement of her right arm knocks her hand against a bell. Each time, she smiles and her vocalizing briefly turns into a laugh.

3. M's music therapy session begins - as ever - with the 'hello' song. And as ever, he makes no discernible response.

4. B startles and then smiles when someone drops a tray of cutlery in the dining room.

5. T brushes her left hand against the strings of guitar that someone is holding near to her. There is a pause and then she raises her hand and brushes the strings again, and then for a third time.

6. Y usually makes a rasping sound as he breathes. He seems to be unaware of what he is doing, and the rasping persists, irrespective of external stimulation. His class teacher has tried to see whether Y can be made aware of his sounds by making them louder (using a microphone, amplifier and speakers), but so far this approach has met with no response.

7. G's teacher notices that he often turns his head towards her when she sings to him, but she has never noticed him turn towards other sounds.

8. W giggles when people repeat patterns of syllables to her such as 'ma ma ma ma ma', 'da da da da da', or 'ba ba ba ba ba'.

9. J's short, sharp vocalizations are interpreted by his teachers and carers to mean that he wants someone to vocalize back to him.

10. K gets very excited when she hears the regular beat on the school's drum machine.

11. U loves 'call and response' games and joins in by making his own sounds.

12. C copies simple patterns of vocalization - imitating the ups and downs of her Speech and Language Therapist's voice.

\footnotetext{
${ }^{6}$ A small, largely enclosed area, originally designed by Lilli Nielsen, which may be placed over a prone child's head and upper torso, and in which potentially sound-making objects and toys are suspended, so that movements the child makes (whether accidentally or deliberately) are likely to create a range of sounds with a good deal of acoustic feedback. At the same time, auditory clutter from the outside is minimised. (For further information, see http://www.lilliworks.com/products.htm)
} 
13. S waves her hand more and more vigorously through an ultrasonic beam, creating an ever wider range of swirling sounds.

14. N often vocalizes in response to vocal sounds that are made close to him, although he does not seem to copy what he hears.

15. Z loves the sound of the bell tree and, when it stops, she rocks in her chair which staff interpret as a gesture for 'more'.

16. D has been able to make a wide range of vocal sounds ever since he started school, but recently he has begun to make more melodious vowel sounds, which he repeats in short sequences.

17. L hums distinct patterns of notes and repeats them. Her favourite sounds rather like a playground chant, and her music teacher notices that she repeats it from one day to the next, though not always starting on the same note.

18. F cries whenever she hears the 'goodbye' song. It only takes the first two or three notes to be played on the keyboard for her to experience a strong emotional reaction.

19. H enjoys copying simple rhythms on an untuned percussion instrument. Now he is started making his own rhythms up too, and he flaps his hands with delight when someone else copies what he is doing.

20. E just laughs and laughs when people imitate her vocalizations.

21. V vocalizes to get his therapist to make a sound - it does not matter what, he just seems to relish having a vocal response.

22. I always gets excited in the middle of the 'slowly/quickly' song - anticipating the sudden change of pace.

23. O scratches the tambourine, making a range of sounds. Whenever he plays near the rim and the bells jingle, he smiles.

24. Q's eye movements intensify when he hears the big band play.

25. X distinctly tries to copy high notes and low notes in vocal interaction sessions.

26. P has learnt to associate his teacher's jangly bracelet, which she always wears, with her: for him, it is an important part of her identity.

The videoed examples were each examined several times in order to refine the ways in which the emergent agreed categorical wording encapsulated the collective views of the observed 
behaviour. It quickly became evident to the Sounds of Intent research team, in the light of examples such as these, that it would be difficult (if not impossible) to conceptualize musical development unidimensionally since, for instance, a child's capacity for attending to sounds may well have outstripped his or her ability to produce them. Hence, at least two dimensions would be required: 'listening and responding', for which the single term 'reactive' was adopted, and 'causing, creating and controlling', for which the label 'proactive' was used. In relation to the examples given above, $1,2,4,7,8,10,15,18,22,23,24$ and 26 could be considered to be entirely or predominantly 'reactive' and 2, 5, 6, 13, 16, 17 and 23 'proactive'. ${ }^{7}$ However, that left a further group of observations (as in examples 3, 9, 11, 12, 14, 19, 20, 21 and 25 above) in which listening to sounds and making them occurred in the context of participation with others, and it was decided that this concept merited the status of a separate dimension, which became known as 'interactive'.

A series of attempts were made to place examples such as those given (and a good many others) along each of the three dimensions - (i) reactive (in response to another), (ii) proactive (initiating behaviour without an obvious external prompt), or (iii) interactive (with another) - basing categorisation on the notion of contingency (that is, by seeking to identify each 'level' as a necessary precursor or possible successor to another or others). For example, it seems clear that an awareness of sound (as in example 2) must precede a differentiated response (as in example 7), which in turn must precede the capacity to anticipate change (example 22). As potential sequences like this emerged, they were mapped onto what is known of 'typical' early musical development (drawing on known literature, such as that referenced in the opening sections earlier in this article) as a way of benchmarking what was being proposed, whilst noting that the generation of new models of progression were not constrained by this prior knowledge, since it was not known just how relevant 'typical' development was to the way in which the musicality of children with complex needs evolves. It was inevitable that this iterative approach to modelling should have been

\footnotetext{
${ }^{7}$ Some observations, such as 23 , related to two dimensions.
} 
adopted, since the evidence available largely comprised snapshots of different children at various stages of development, rather than longitudinal data on the same children as they matured, which would have offered some degree of greater certainty as to the nature of developmental change. Taking a more heuristic tack, though, was deemed valid as a preliminary step for two reasons: first, since it was not yet known what the appropriate data to collect would be; and second, since meaningful longitudinal studies of children with complex needs would be likely to last for several years at least. However, it was felt that once an initial model had been developed, this could subsequently be used to inform longer-term empirical work - as well as being informed by it.

The project team decided first to try to identify if there were key phases in the recognition and understanding of musical structure that young people with the more extreme forms of complex needs (profound and multiple learning difficulties - PMLD) were likely to follow. Using the iterative process described above, five broad levels of attainment were established:

- $\quad$ a developing awareness of sound (including musical sound);

- $\quad$ a developing awareness of the variety of sounds that are possible;

- a developing awareness of simple patterns within sound brought about through repetition or variation, whereby sounds seem to form coherent clusters or streams ('groups'); and

- a developing awareness that groups of sounds may themselves be repeated or varied, and thereby have a sense of connectedness.

In terms of their emotional response to music, it seemed likely that children with PMLD reacted to the basic qualities of sound (high/low, loud/soft, quick/slow, and so on) in the same way as children who were chronologically in the first few months of life - reactions that seem likely to relate to features of maternal vocalisation (Trehub \& Nakata, 2001/2002). However, as the children's awareness 
of how sound is structured in music developed (as above), it was felt that their capacity to respond evolved also. Hence, there was evidence of young people with PMLD being able to anticipate changes in loudness, tone-colour or pitch, for example, from previous hearings, and evidently relishing the feeling that having their expectations fulfilled brought.

In more detail, we sought to chart musical development in the domain of profound and multiple learning difficulties as follows. At first, children appear to encounter sounds with little or no understanding of what these sensations mean, how they are caused or how they may be elicited; interactions with others in the domain of sound and music may occur - but only by chance. Second, there may be an emerging sense of awareness of sound and silence, and intentionality in the production of sound, which may be made in response to external stimuli or, in turn, used to stimulate a response. Third, children may attend and respond to a variety of sounds; they may be able to make a range of different sounds (or cause them to be made), and they may take turns without copying what is heard or noticing if their own sounds are copied. Fourth, children may recognise and respond to simple patterns in sound - straightforward repetition and variation that may enable them to anticipate what is coming next. They may produce simple patterns by deliberately repeating or varying the sounds they make, and they may take turns, copying individual sounds that they hear and relishing their own sounds being copied. Fifth, children may respond distinctly to familiar short pieces, fragments or features of music, and may be able to anticipate clearly delineated contrasts within them. They may be able to repeat short groups of sounds, which may incorporate recognisable fragments or features of music that they have heard. They may take turns in copying short patterns in sound and anticipating their own short patterns being copied.

In the course of the research process, various ways of depicting proposed patterns of development such as that outlined above were considered that would make them quickly and easily accessible to ourselves and to others, such as teachers, whilst somehow representing visually the idea that one level builds on those preceding without replacing them. The team also wanted the framework 
to give a general feeling of growth and expansion - of moving 'out' into the world from an inner core. After several attempts, an approach was adopted that used segments within concentric circles (Figure $1^{8}$ ). This model, including refinements to the wording, emerged over a two-year period (July 2003August 2005) in the light of iterative, group-based analyses of videoed case study data from over twenty children in different schools.

\section{INSERT FIGURE 1 ABOUT HERE}

Figure 1: The Sounds of Intent musical development framework. The framework has been developed over the past five years (with extensive modifications being undertaken) in the search for a design that is appropriate for providing the research team and others, such as teachers, with a simple though sufficiently detailed tool for the assessment of musical behaviours observed in pupils with the most extreme form of complex needs, PMLD. See Ockelford, Welch, Zimmermann \& Himonides (2004; 2005) for more information.

\section{Aim}

It became clear that the emergent developmental framework needed a more extensive evaluation across a wider population and so sustained fieldwork was undertaken in participant schools over two years (September 2005 to August 2007). This article focuses on the data collection and analyses from Year 1 of the Sounds of Intent project. The prime focus for the first year of the project was to gather evidence as to the appropriateness (validity and reliability) of the emergent framework (as shown in Figure 1) - in the sense of seeking confirmation or otherwise that observed behaviours had a correspondence to the current version of the framework in relation to understanding the musicrelated behaviours of the group we were researching.

${ }^{8}$ Note: 'Encounters sound' in the inner part of the Reactive segment means that the child/young person is in the presence of sound, but with no noticeable reaction. 


\section{Method}

The original research project working group was expanded and reconstituted as a project Advisory Group with continued membership drawn from practitioners working with children and young people with complex needs, including music therapy and education specialists as well as selfidentified 'non-specialists' in music. Subsequently, five special schools in the South East of England were invited to participate, based on their previously expressed interest in the research through professional networks associated with the Advisory Group. Once the appropriate ethical permissions had been secured (in line with British Educational Research Association ethical guidelines), a series of consecutive visits across two school terms were made to each of the five schools to gather observational data. All observations were made by the part-time Research Officer and each pupil was observed in the context of a whole-class music activity. The Research Officer was asked to focus on one child at a time and one particular behaviour in response to the teacher's activity (which often tended to focus on individual children). Teachers were asked to allow the Research Officer to sit in on a normal music session, rather than anything specially designed for the project. No attempt was made to standardise the musical activities across classes or schools. (Examples of the types of activities observed are implied in the 'observations' section above.) The numbers of pupils observed in each school group varied according to the size of the school and the numbers of PMLD pupils that they contained. In school 1, 6 children were observed; in school 2, 10; the remaining numbers of participants for schools 3, 4 and 5 were 17, 28 and 7 respectively, making a total of 68 pupils.

Observations were undertaken in two schools each week over successive weeks arranged in school half-term periods (up to six weeks in succession - including initial preparatory visits). Subsequent categorisations of musical behaviours were undertaken in discussion with the pupils' class teachers. The initial visits within Term 1 were treated as a 'pilot', in the sense that the framework (having evolved from previous case study analyses of individual video recordings) could also be used in real time in the classroom. These initial, school-based observations were videoed for subsequent analysis 
back at the university by the team and discussion with colleagues within the project Advisory Group, including the teachers who were members of the Group whose pupils had been observed. Additionally, the Research Officer was mentored in the classroom observation process by one of the original research team to ensure a consistency of research approach in the classroom.

The layout of the developmental framework was adapted (Figure 2) for observational use in the music classroom with a tablet PC (or any other kind of personal computer) and trialled by two members of the research team. In essence, the approach adopted was one of mapping case study examples of observed musical behaviours from individual children and young people onto the headings identified in the framework. Where there was uncertainty, the Research Officer and teacher practitioners would present video evidence to the Group, and issues would be resolved through discussion ${ }^{9}$.

\section{INSERT FIGURE 2 ABOUT HERE}

Figure 2: The Sounds of Intent musical development framework - arranged for observational use in the classroom on a tablet PC (version 1)

\section{Key findings from the Sounds of Intent project fieldwork observations in Year 1}

The research findings from the Year 1 of the Sounds of Intent project produced a large amount of observational data from the five participating schools. During the Spring and Summer terms (January to July 2006), the Sounds of Intent framework was tested in relation to the musical behaviours of 68 children and young people with complex needs. In total, 630 observations were made for the 68 participants. Their ages ranged from $4 \mathrm{y} 7 \mathrm{~m}$ to $19 \mathrm{y} 1 \mathrm{~m}$, with an average age of $13 \mathrm{y} 1 \mathrm{~m}$. There was a slight bias towards male participation (male 59\%, female $41 \%$ ).

\footnotetext{
${ }^{9}$ As mentioned earlier, the format and detailed wording of the model (Figure 1) had already undergone a two-year development prior to the new fieldwork phase, using group-based observations of individuals with PMLD who had been videoed. Revisions had been made to the wording over this period to reduce any possible ambiguities to the minimum in order to ensure that observed behaviours could be assigned to a given category.
} 
As mentioned above, the Sounds of Intent PMLD framework comprises three segments, each containing five levels, with movement from the centre outwards to the periphery of the circle being marked by more advanced musical behaviours in each segment (see Figure $1^{10}$ ). In each segment (Reactive, Proactive, Interactive), there is a tendency for the observational data to exhibit (i) a bias towards the mid point (levels $2 / 3$ of the 5 level scale), with Interactive observations tending to be skewed towards a slightly lower level (see Figure 3); and (ii) relatively few observations in the most advanced levels of each segment (levels 4 and 5).

\section{INSERT FIGURE 3 ABOUT HERE}

FIGURE 3: Number of observations $(\mathrm{n}=630)$ by Sounds of Intent musical behaviour framework category $(\mathrm{R}=$ Reactive, $\mathrm{P}=$ Proactive, $\mathrm{I}=$ Interactive - see Figure 1$)$ for $\mathrm{n}=68$ Year 1 participants with complex needs, 2006.

In addition, there was very little difference between the numbers of observations recorded for each of the three segments $($ Reactive $=217$; Proactive $=208$; Interactive $=205$; see Table 2 ) for the 68 participants.

\section{INSERT TABLE 2 ABOUT HERE}

Table 1: The number and percentage of classroom-based observations for each of the three Sounds of Intent framework segments (Reactive, Proactive, Interactive) for 68 participants in the 5 Year 1 project schools

The differences in the distribution of the observed ratings (Chi-square $=10.4$, df $4, \mathrm{p}<.05)$ are significant between the five levels across the three segments, confirming the bias towards the middle level categories. Nevertheless, there are similarities in the patterns of observations (Kendall's Coefficient of Concordance $(\mathrm{W})=.86$ ). The principle difference between pattern of observations

${ }^{10}$ Each successive element (moving outwards) includes any behaviours described within its inner elements. The outer layer (R5, P5, I5 embraces all the elements from the centre outwards in their segment, i.e., R1 is the centremost element of the Reactive segment; R2 is next moving outwards and the wording is designed to be more advanced than R1, etc. 
within and across the three segments $(R, P, I)$ is that the Interactive set are skewed more towards the lower level (around level 2) compared to the Reactive and Proactive observations (around level 3). There is a strong correlation between Reactive and Proactive patterns of observations $(\mathrm{r}=.927, \mathrm{p}<.05)$; whereas there is a much lower correlation between Reactive and Interactive patterns $(\mathrm{r}=.458$, nonsignificant) and between Proactive and Interactive $(\mathrm{r}=.673$, also non-significant).

A comparison between the five schools indicates that there was a relatively high degree of similarity in the pattern of the observations for each location (Kendall's Coefficient of Concordance $(\mathrm{W})$ for Reactive $=.737$; Proactive $=.755$; Interactive $=.800$; each $\mathrm{p}<.05$ ). This finding implies: (a) that a common approach was adopted in the research application of the framework and process of observation across the five school sites (and endorsed by team reviews of sample videoed observations) and (b) that the schools had similar patterns of Reactive, Proactive and Interactive observational data amongst their pupils.

With regard to the pattern of observations in relation to the sex of the participants, there is a significant correlation in the data between scores across the fifteen (three $\mathrm{x}$ five) levels for the sexes (Table $3 ; \mathrm{r}=.979, \mathrm{p}<.001$ ), with no significant differences between the sexes in numbers of observations on any of the three segments (Reactive, Proactive and Interactive) (see Figure 4).

INSERT TABLE 3 ABOUT HERE

TABLE 2: Numbers of observations within each Sounds of Intent framework segment and level by sex

INSERT FIGURE 4 ABOUT HERE

FIGURE 4: Mean observation rating by Sounds of Intent segment x sex of participants 
With regard to longitudinal change over time, one school (CM) generated ten successive weeks of observations for seven children (with only a few individual absences) across one school term. Of the seven children, four (57\%) were exhibiting more advanced musical behaviours in the final week compared to their first session, one had made no change and two (29\%) were rated at slightly lower levels (see Table 4).

\section{INSERT TABLE 4 ABOUT HERE}

TABLE 3: Longitudinal data on the observed musical behaviour of seven children in one school over a ten-week period. Framework levels (1-5) have been summed within the two comparison weeks (1 and 10 ) in order to generate a notion of observed 'change' during this period

Overall, an analysis that examined the age of the participants set against the observed rating of their mean musical behaviours on the framework revealed that there was a weak relationship $(r=.289$, $\mathrm{p}=.018$ ) between age and observed rating, with older participants tending to be more highly rated on the Sounds of Intent framework (Figure 5). Notwithstanding any clustering and age-related trend in the data, inspection of the scatterplot reveals a wide variation at the level of the individual, with some young participants being much more highly rated than their older peers.

\section{INSERT FIGURE 5 ABOUT HERE}

FIGURE 5: Sounds of Intent framework mean individual segment ratings by age of participant

\section{Discussion}

Overall, analysis of the emergent Year 1 data for the Sounds of Intent project (i) is supportive of the general design features of the current version of the observational framework and (ii) offer some 
initial evidence that music development is a concept that can be applied in the context of complex needs, specifically to those children and young people categorised as having profound and multiple learning difficulties, although we recognise that robust longitudinal data are also needed (and are currently being collected in a new phase of research). Overall, relatively few participants had their musical behaviours rated at the base level of the framework (level 1, i.e. 112 out of 630 observations, $18 \%$ ), whereas the vast majority of behaviours (518 out of $630,82 \%$ ) were identified as having some sense of personal agency, such as 'makes sound in response to an external stimulus' (Interactive, level 2) and 'makes sounds intentionally' (Proactive, level 2). Although very small numbers of behaviours were classified at the most advanced framework level (level 5), a distinct minority of behaviours (approximately $8 \%, 50$ out of 630 observations) were classified as having distinctive musical features, such as the production of simple patterns through repetition (Proactive, level 4).

The wider context for these observations is a special school sector in which music, although reportedly a welcome component in school life, it is not strongly evidenced in local curricula or specialist staffing for the majority (Welch et al, 2001). OfSTED (the UK Government's Office for Standards in Education) does not provide summative school inspection data for music, although in the past their reports on individual schools have often been positive about the possibilities offered by music for promoting other forms of development, such as social, motor and communication skills (Ockelford, 2008). Nevertheless, the data reported here indicate that education in music, as well as education through music, is possible. Moreover, the data were generated from individuals in participant schools who had volunteered to take part in the project, not least because their head teachers were pleased to recognise the value of music education for their pupils. Therefore, the evidence of possible positive change in a relatively short period of one school term for one group of participants (Table 4) is to be welcomed ${ }^{11}$, as is the suggestion that an increased exposure to music over time offers the

${ }^{11}$ The second year of the Sounds of Intent project has also sought opportunities to revisit case study participants to determine if any noted changes continue to be evidenced in the longer term. 
potential for longer-term development, at least for some (Figure 5). Such positive findings highlight what might be possible if the special education sector were able to address the relative absence of systematic music education for the majority of its pupils with complex needs, a weakness evidenced in the findings of the PROMISE survey (Welch, et al, 2001) and an earlier OfSTED review (1999, p. 31) in which 'only half of the teaching was reported as satisfactory or better' and in a third of schools 'not enough music lessons were seen to provide a secure judgement on pupils' progress, or that music was not taught.' (op.cit., p. 23). It seems unfortunate that current OfSTED policy appears to be not to comment on the standards of special school teaching and learning in music, given that $55 \%$ of schools are reported to have 'some' or 'substantial improvement required' in their provision for 'pupils' cultural development' (OfSTED, 2004, p. 34) - the only likely current inspection report category that might include music.

\section{Conclusion}

Although we recognise that further systematic investigation is needed (in a context where there has been 'scant research on the topic of music learning and children with disabilities' - Jellison, 2006:270), such as the gathering of more robust longitudinal data from a diversity of settings, we believe that this first year has provided a positive basis on which to build. The Sounds of Intent framework may be seen as a 'tool' by which the researchers and teachers working with pupils with complex needs can (a) make an initial informed judgement of where a particular pupil appears to be 'now' musically and (b) be encouraged to design musical activities that might enable the pupil to develop towards a more advanced level. A particular focus for the second year of the project (20062007) has been to observe special needs teacher activity in the music classroom and attempt to see how this might link to the observed pupil behaviour. Drawing on activity theory ( $c f$ Welch, 2007), for example, we believe that musical behaviours often (but not always) appear in relation to particular contexts and we will be exploring this feature further in future case study data collection and analyses. 
We are also exploring how the current framework might be extended outwards to encompass the musical behaviours of children and young people with less severe learning difficulties within the complex needs field.

\section{Acknowledgements}

This research has been undertaken with financial support from the Esmée Fairbairn Foundation, grant reference ED/04-2843. The authors also take this opportunity to acknowledge the high level of support provided by teachers, children, young people and their carers in the participant schools, as well as the expert guidance of the project Advisory Group.

\section{References}

Cassidy, J.W. (1992). Communication disorders: Effects on children's ability to label musical characteristics. Journal of Music Therapy, 29(2), 113-124.

Darrow, A.A. (1984). A comparison of rhythmic responsiveness in normal and hearing impaired children and an investigation of the relationship of rhythmic responsiveness to the suprasegmental aspects of speech perception. Journal of Music Therapy, 21(2), 48-66.

DfES/ONS. (2005). Special Educational Needs in England, January, 2005. London: DfES. [Report SFR 24/2005].

Dey, I. (2007). Grounding Categories. In: A. Bryant, \& K. Charmaz (Eds), Grounded Theory. (pp. $167-$ 190). London: Sage Publications.

Fassbender, C. (1996). Infants' auditory sensitivity towards acoustic parameters of speech and music. In: I. Deliege \& J. Sloboda (Eds), Musical Beginnings. (pp. 56-87). New York: Oxford University Press. 
Flowers, P.J., \& Wang, C. (2002). Matching verbal description to music excerpt: The use of language by blind and sighted children. Journal of Research in Music Education, 50(3), 202-214.

House of Commons Education and Skills Committee. (2006). Special Educational Needs Third Report of Sesssion 2005-06, Volume 1. London: The Stationery Office. [6 July 2006].

Jellison, J.A. (2000). A content analysis of music research with disabled children and youth (19751999). In: Effectiveness of music therapy procedures: Documentation of research and clinical practice. (pp. 199-264). Silver Spring, MD: The American Music Therapy Association.

Jellison, J.A. (2006a). What research tells us about music and the needs of children in special education. Proceedings, Beijing International Forum on Music Education 2006. (pp. 235-248). May 15-17, Beijing: NAMM/CSME/ISME/CNU.

Jellison, J.A. (2006b). Including everyone. In: G. McPherson (Ed), The Child as Musician. (pp. 257272). New York: Oxford University Press.

Jellison, J.A., \& Taylor, D.M. (2007). Attitudes toward inclusion and students with disabilities: A review of three decades of music research. Bulletin of the Council for Research in Music Education, 172, 9-23.

Lecanuet, J-P. (1996). Prenatal auditory experience. In: I. Deliege \& J. Sloboda (Eds), Musical Beginnings. (pp. 3-34). New York: Oxford University Press.

MacDonald, R.A.R., J.B., Davies, \& O'Donnell, P.J. (1999). Structured music workshops for individuals with learning difficulty: an empirical investigation. Journal of Applied Research in Intellectual Disabilities 12(3) 225 - 241.

Molino, J. (2000). Towards an evolutionary theory of music and language. In: N. Wallin, B. Merker \& S.Brown (Eds), The Origins of Music (pp. 165-176). Cambridge, MA: MIT Press.

Ockelford, A. (2000). Music in the Education of Children with Severe or Profound Learning Difficulties: Issues in Current UK Provision, A New Conceptual Framework and Proposals for Research. Psychology of Music, 28 (2), 197-217. 
Ockelford, A. (2008). Music for Children and Young People with Complex Needs. Oxford: Oxford University Press.

Ockelford, A., Pring, L., Welch, G. F., \& Treffert, D. (2006). Focus on Music: Exploring the musical interests and abilities of blind and partially-sighted children with septo-optic dysplasia. London: Institute of Education/RNIB. [pp71]

Ockelford, A., Welch, G.F. \& Zimmermann, S.-A. (2002). Music education for pupils with severe or profound and multiple difficulties - current provision and future need. British Journal of Special Education, 29 (4), 178-182.

Ockelford, A., Welch, G.F., Zimmermann, S-A., \& Himonides, E. (2004). Sounds of Intent. Eye Contact, 40, 12-15.

Ockelford, A., Welch, G. F., Zimmermann, S.-A., Himonides, E. (2005). "Sounds of intent" - mapping, assessing and promoting the musical development of children with profound and multiple learning difficulties. Proceedings of "VISION 2005" conference, 4-7 April 2005. London: Royal National Institute of the Blind. Elsevier: International Congress Series, 2005, vol. 1282, pp. 898902.

O’Donnell, P.J., MacDonald, R.A.R. \& Davies J.B. (1999). Video analysis of the effects of structured music workshops for individuals with learning difficulties. In: D. Erdonmez, \& R.R. Pratt, (Eds.) Music Therapy \& Music Medicine: Expanding Horizons. (pp. 219-228). Saint Louis: MMB Music.

OfSTED (1999). Special Education 1994-1998: A review of special schools, secure units and pupil referral units in England. London: The Stationery Office.

OfSTED (2004). Performance Assessment and National Contextual Data (PANDA) for Special Schools. Retrieved from http://www.ofsted.gov.uk/portal/site/Internet/menuitem.eace3f09a603f6d9c3172a8a08c08a0c/? vgnextoid=43f9c30f8636c010VgnVCM1000003507640aRCRD February 9, 2007. 
Papoušek, H. (1996). Musicality in infancy research: biological and cultural origins of early musicality.

In: I. Deliege \& J. Sloboda (Eds), Musical Beginnings. (pp. 37-55). New York: Oxford University Press.

Papoušek, M. (1996). Intuitive parenting: a hidden source of musical stimulation in infancy. In: I.

Deliège, \& J. A. Sloboda (Eds), Musical Beginnings. (pp. 88-112). New York: Oxford University Press.

Parncutt, R. (2006). Prenatal development. In: G. McPherson (Ed), The Child as Musician. (pp. 1-31).

New York: Oxford University Press.

Qualifications and Curriculum Authority [QCA]. (2001). Planning, teaching and assessing the curriculum for pupils with learning difficulties: Music. London: QCA.

Rankin, J. \& Regan, S. (2004). Meeting Complex Needs: The Future of Social Care, London: Turning Points/ Institute of Public Policy Research (IPPR).

Rosengard, A., Laing, I., Ridley, J., \& Hunter, S. (2007). A literature review of multiple and complex needs. Edinburgh: Scottish Executive. Available from Scottish Executive Scottish Social Research website www.scotland.gov.uk/socialresearch

Stordahl, J. (2002). Song recognition and appraisal: A comparison of children who use cochlear implants and normally hearing children. Journal of Music Therapy, 39(1), 2-19.

Swedberg, O. (2007). A comparison of hearing and deaf/hard-of-hearing students' use of analytic, figurative and temporal language in descriptions of music. Unpublished Masters of Music Education Thesis, College of Music, Florida State University.

Trehub, S. (1990). The perception of musical patterns by human infants: the provision of similar paterns by their parents. In: M. A. Berkeley \& W. C. Stebbins (Eds), Comparative perception, Vol. 1: Basic mechanisms. (pp 429-459). Chichester: Wiley.

Trehub, S. (2003). Musical Predispositions in Infancy: An Update. In: I. Peretz, \& R. Zatorre (Eds). The Cognitive Neuroscience of Music. (pp. 3-20). New York: Oxford University Press. 
Trehub, S. (2006). Infants as musical connoisseurs. In: G. McPherson (Ed.), The Child as Musician. (pp. 33-49). New York: Oxford University Press.

Trehub, S., \& Nakata, T. (2001/2002). Emotion and music in infancy. Musicae Scientiae Musicae Scientiae, Special Issue: Current Trends in the Study of Music and Emotion, 37-61.

Trevarthen, C. (2002). Origins of musical identity: evidence from infancy for musical social awareness. In: R. MacDonald, D. Hargreaves, \& D. Miell (Eds.), Musical Identities. (pp. 21-38). New York: Oxford University Press.

Welch, G.F. (2005). Singing as Communication. In: D. Miell, R. MacDonald \& D. Hargreaves (Eds.), Musical Communication. (pp. 239-259). New York: Oxford University Press.

Welch, G.F. (2007). Addressing the multifaceted nature of music education: an activity theory research perspective. Research Studies in Music Education, 28, 23-38.

Welch, G.F., Ockelford, A. \& Zimmermann, S-A. (2001). Provision of Music in Special Education PROMISE. Royal National Institute for the Blind/University of London Institute of Education. [pp59] 


\section{Framework of musical development in the domain of PMLD}

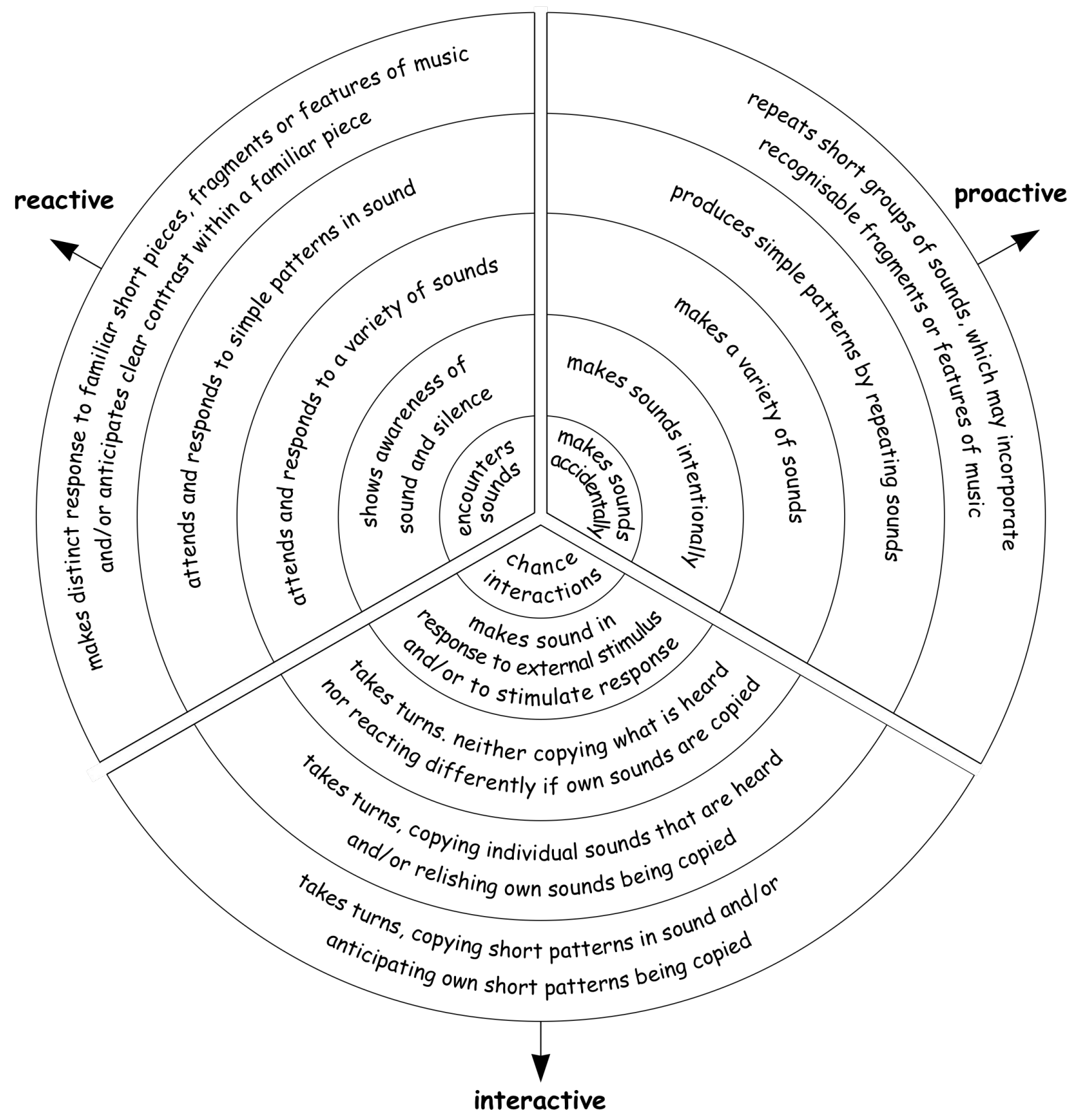



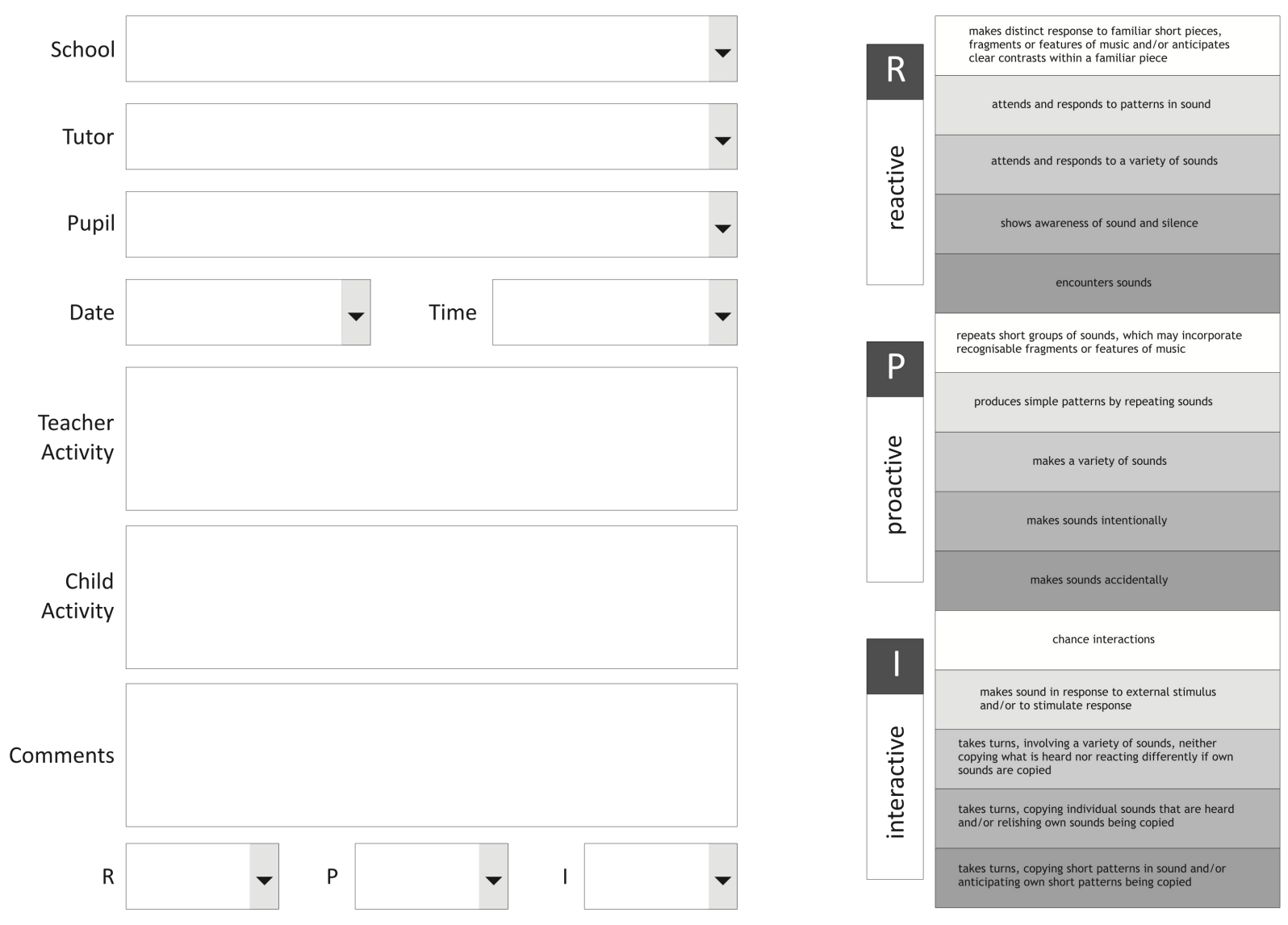


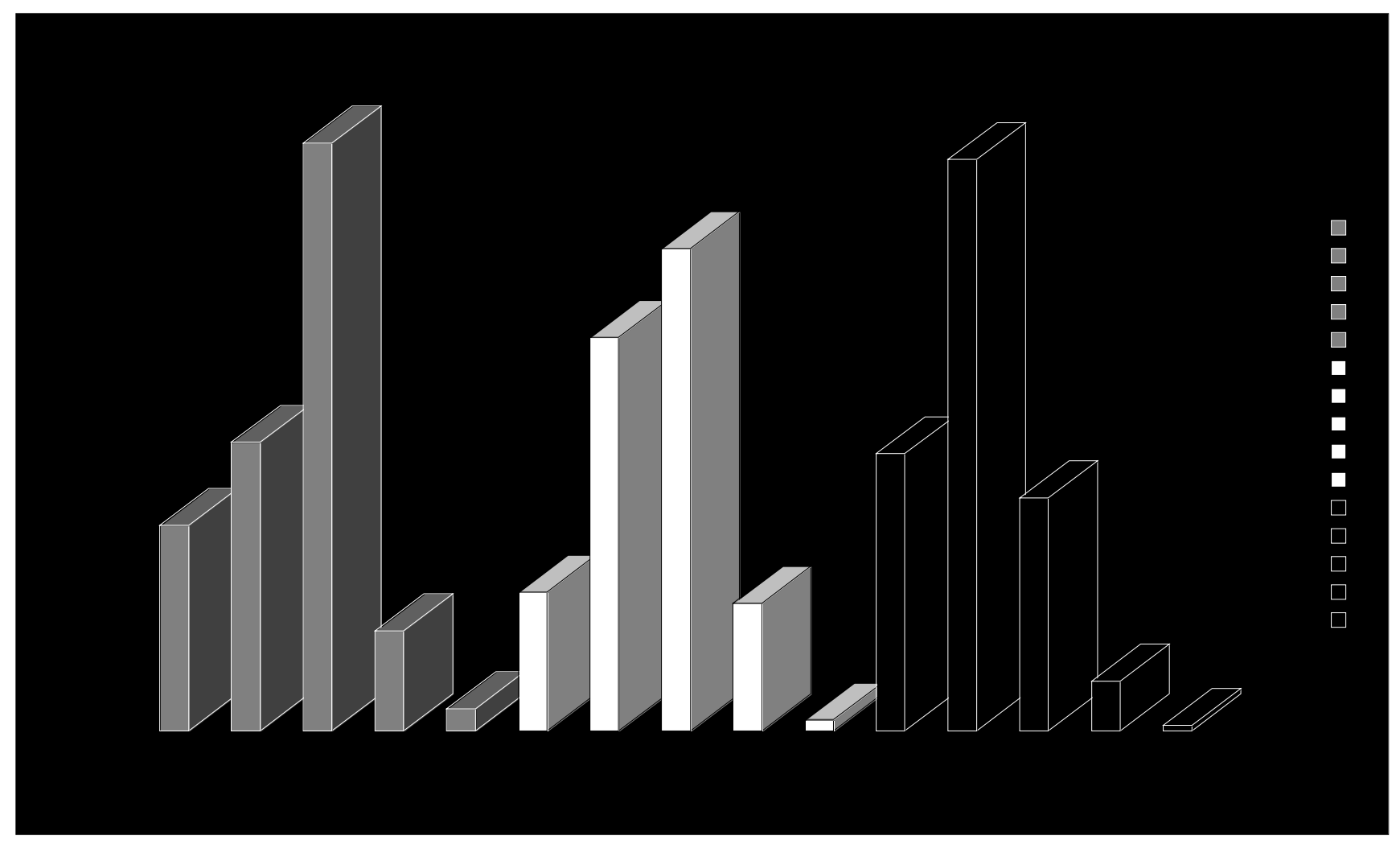

FIGURE 3: Number of observations $(\mathrm{n}=630)$ by Sounds of Intent musical behaviour framework category

$(\mathrm{R}=$ Reactive, $\mathrm{P}=$ Proactive, $\mathrm{I}=$ Interactive - see Figure 1$)$ for $\mathrm{n}=68$ Year 1 (2006) participants with complex needs 



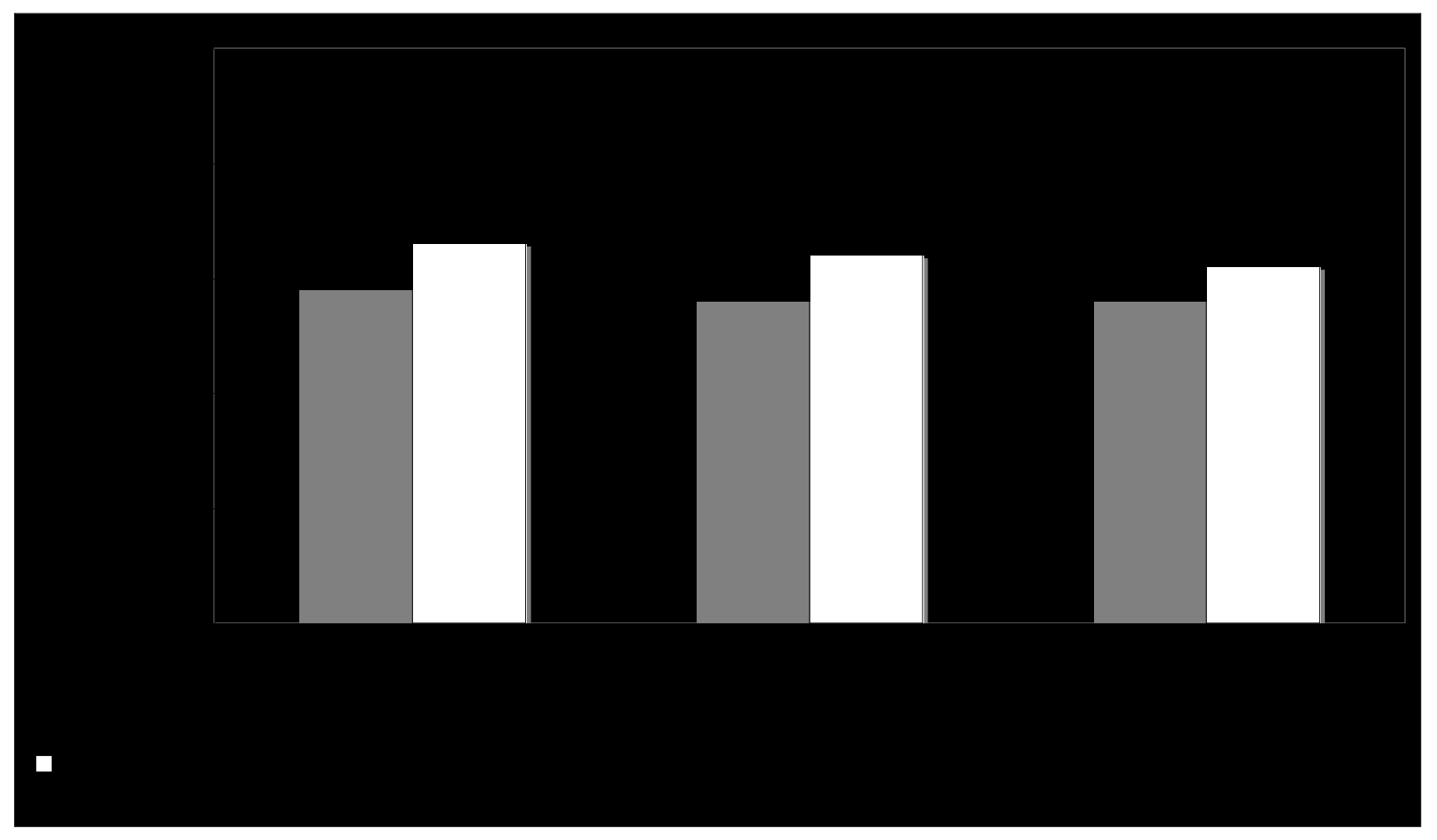

FIGURE 4: Mean observation rating by Sounds of Intent segment x sex of participants 


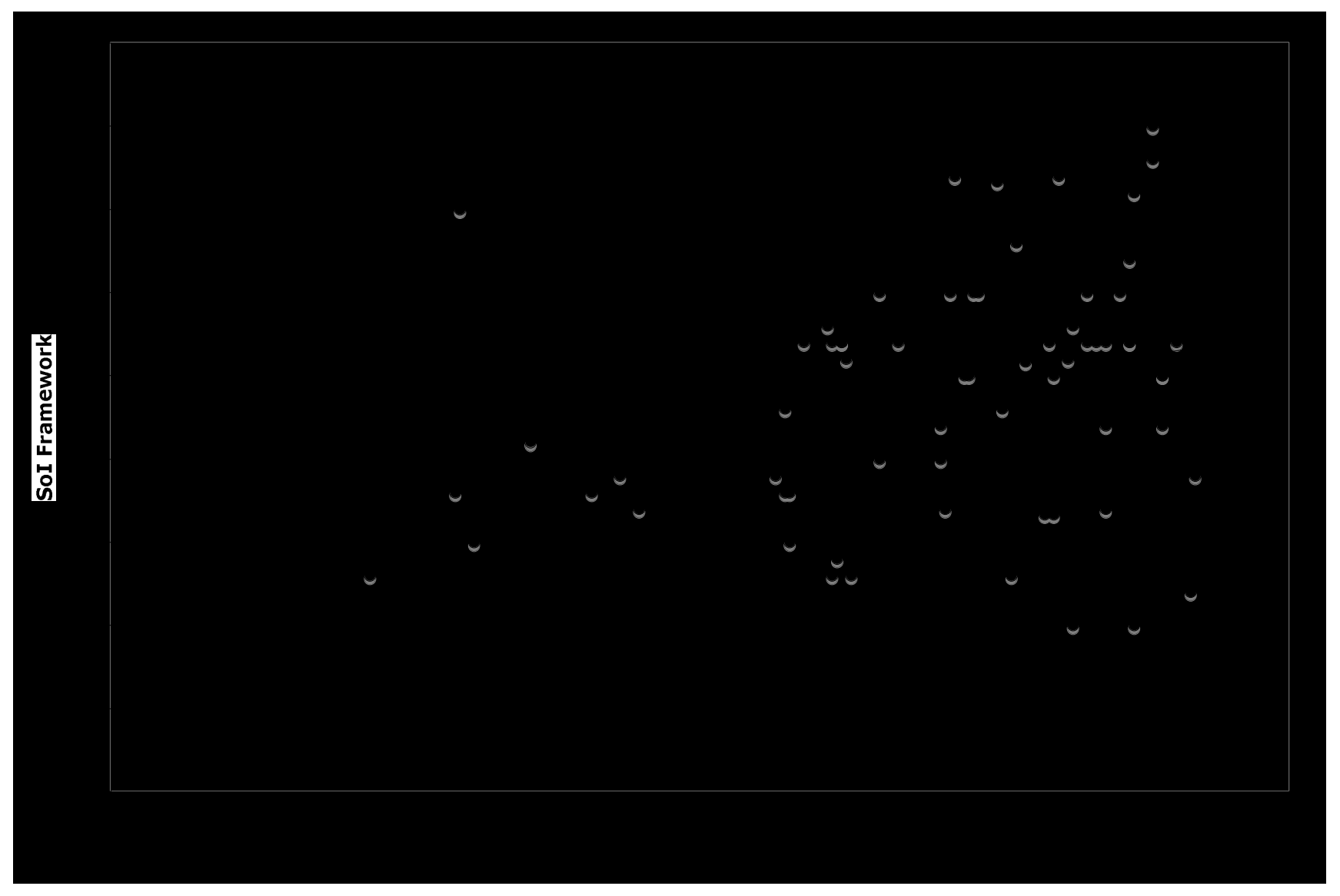

FIGURE 5: Sounds of Intent framework mean individual segment ratings by age of participant $(\mathrm{n}=68)$ 


\begin{tabular}{|c|c|c|c|}
\hline Level & Listening, reacting and responding & $\begin{array}{l}\text { Causing, creating and controlling } \\
\text { (alone or with others) }\end{array}$ & $\begin{array}{l}\text { Reflecting on / communicating } \\
\text { about music }\end{array}$ \\
\hline P1(i) & $\begin{array}{l}\text { Pupils encounter activities and } \\
\text { experiences. } \\
\text { They may be passive or resistant. } \\
\text { They may show simple reflex } \\
\text { responses, for example, startling at } \\
\text { sudden noises or movements. }\end{array}$ & Any participation is fully prompted. & \\
\hline P1(ii) & $\begin{array}{l}\text { Pupils show emerging awareness of } \\
\text { activities and experiences. } \\
\text { They may have periods when they } \\
\text { appear alert and ready to focus their } \\
\text { attention on certain people, events, } \\
\text { objects or parts of objects, for } \\
\text { example, becoming still in a concert } \\
\text { hall. } \\
\text { They may give intermittent } \\
\text { reactions, for example, sometimes } \\
\text { becoming excited at repeated } \\
\text { patterns of sounds. }\end{array}$ & & \\
\hline P2(i) & $\begin{array}{l}\text { Pupils begin to respond consistently } \\
\text { to familiar people, events and } \\
\text { objects. } \\
\text { They react to new activities and } \\
\text { experiences, for example, turning } \\
\text { towards unfamiliar sounds. } \\
\text { They begin to show interest in } \\
\text { people, events and objects, for } \\
\text { example, looking for the source of } \\
\text { music. }\end{array}$ & $\begin{array}{c}\text { They accept and engage in coactive } \\
\text { exploration, for example, being } \\
\text { encouraged to stroke the strings of a } \\
\text { guitar. }\end{array}$ & \\
\hline P2(ii) & $\begin{array}{l}\text { They recognise familiar people, } \\
\text { events and objects, for example, } a \\
\text { favourite song. }\end{array}$ & $\begin{array}{l}\text { Pupils begin to be proactive in their } \\
\text { interactions. } \\
\text { They perform actions, often by trial } \\
\text { and improvement, and they } \\
\text { remember learned responses over } \\
\text { short periods of time, for example, } \\
\text { repeatedly pressing the keys of an } \\
\text { electronic key board instrument. } \\
\text { They cooperate with shared } \\
\text { exploration and supported } \\
\text { participation, for example, holding } \\
\text { an ocean drum. }\end{array}$ & $\begin{array}{l}\text { They communicate consistent } \\
\text { preferences and affective responses, } \\
\text { for example, relaxing during certain } \\
\text { pieces of music but not others. }\end{array}$ \\
\hline P3(i) & $\begin{array}{l}\text { They sustain concentration for short } \\
\text { periods. } \\
\text { They observe the results of their own } \\
\text { actions with interest, for example, } \\
\text { listening intently when moving } \\
\text { across and through a sound beam. }\end{array}$ & $\begin{array}{l}\text { They participate in shared activities } \\
\text { with less support. } \\
\text { They explore materials in } \\
\text { increasingly complex ways, for } \\
\text { example, tapping piano keys gently } \\
\text { and with more vigour. }\end{array}$ & $\begin{array}{l}\text { Pupils begin to communicate } \\
\text { intentionally. } \\
\text { They seek attention through eye } \\
\text { contact, gesture or action. } \\
\text { They request events or activities, for } \\
\text { example, leading an adult to the } C D\end{array}$ \\
\hline
\end{tabular}




\begin{tabular}{|c|c|c|c|}
\hline & $\begin{array}{l}\text { They remember learned responses } \\
\text { over more extended periods ... }\end{array}$ & $\begin{array}{l}\text {.. for example, recalling movements } \\
\text { associated with a particular song } \\
\text { from week to week. }\end{array}$ & player. \\
\hline P3(ii) & $\begin{array}{l}\text { They can remember learned } \\
\text { responses over increasing periods of } \\
\text { time and may anticipate known } \\
\text { events, for example, a loud sound at } \\
\text { a particular point in a piece of } \\
\text { music. }\end{array}$ & $\begin{array}{l}\text { They actively explore objects and } \\
\text { events for extended periods, for } \\
\text { example, tapping, stroking, rubbing } \\
\text { or shaking an instrument to produce } \\
\text { various effects. }\end{array}$ & $\begin{array}{l}\text { Pupils use emerging conventional } \\
\text { communication. } \\
\text { They greet known people and may } \\
\text { initiate interactions and activities, } \\
\text { for example, performing an action } \\
\text { such as clapping hands to initiate a } \\
\text { particular song. } \\
\text { They may respond to options and } \\
\text { choices with actions or gestures, for } \\
\text { example, choosing a shaker in a } \\
\text { rhythm band activity. } \\
\text { They apply potential solutions } \\
\text { systematically to problems, for } \\
\text { example, indicating by eye contact } \\
\text { or gesture the pupil whose turn it is } \\
\text { to play in a 'call and response' } \\
\text { activity. }\end{array}$ \\
\hline
\end{tabular}

Table 1: An analysis of formal 'Performance Descriptions' (as published by the UK Qualifications and Curriculum Authority - QCA) in one of three musical domains 


\begin{tabular}{|c|c|c|c|c|c|}
\hline & \multicolumn{5}{|c|}{ REACTIVE BEHAVIOURS } \\
\hline SoI Segments & $\underline{\mathbf{R 1}}$ & $\underline{\mathbf{R 2}}$ & $\underline{\mathbf{R 3}}$ & $\underline{\mathrm{R4}}$ & $\underline{\mathbf{R 5}}$ \\
\hline Numbers & 37 & 52 & 106 & 18 & 4 \\
\hline SoI Segments & $\underline{\mathbf{R} 1}$ & $\underline{\mathbf{R 2}}$ & $\underline{\mathbf{R 3}}$ & $\underline{\mathbf{R 4}}$ & $\underline{\mathbf{R 5}}$ \\
\hline$\%$ & $5 . \overline{87 \%} \%$ & $8 . \overline{25 \%}$ & $16.83 \%$ & $2 . \overline{86} \%$ & $0 . \overline{63 \%}$ \\
\hline \multicolumn{2}{|l|}{ Segment totals } & & 217 & & \\
\hline & \multicolumn{5}{|c|}{ PROACTIVE BEHAVIOURS } \\
\hline SoI Segments & $\underline{\mathbf{P 1}}$ & $\underline{\mathbf{P 2}}$ & $\underline{\mathbf{P 3}}$ & $\underline{\mathrm{P4}}$ & $\underline{\mathrm{P5}}$ \\
\hline Numbers & 25 & 71 & 87 & 23 & 2 \\
\hline SoI Segments & $\underline{\mathbf{P 1}}$ & $\underline{\mathbf{P 2}}$ & $\underline{\mathbf{P 3}}$ & $\underline{\mathbf{P 4}}$ & $\underline{\mathbf{P 5}}$ \\
\hline$\%$ & $3.97 \%$ & $11.27 \%$ & $13.81 \%$ & $3.65 \%$ & $0.32 \%$ \\
\hline \multicolumn{2}{|l|}{ Segment totals } & & 208 & & \\
\hline & \multicolumn{5}{|c|}{ INTERACTIVE BEHAVIOURS } \\
\hline SoI Segments & $\underline{I 1}$ & $\underline{I 2}$ & $\underline{\mathbf{I 3}}$ & $\underline{\mathrm{I4}}$ & $\underline{\mathrm{I5}}$ \\
\hline Numbers & 50 & $\overline{103}$ & $\overline{42}$ & $\overline{9}$ & $\overline{1}$ \\
\hline SoI Segments & $\underline{I 1}$ & $\underline{I 2}$ & $\underline{\text { I3 }}$ & $\underline{\mathrm{I4}}$ & $\underline{\mathrm{I5}}$ \\
\hline$\%$ & $7 . \overline{94} \%$ & $16 . \overline{35} \%$ & $6 . \overline{67} \%$ & $1 . \overline{43} \%$ & $0 . \overline{16} \%$ \\
\hline \multicolumn{2}{|l|}{ Segment totals } & & 205 & & \\
\hline \multirow{4}{*}{ 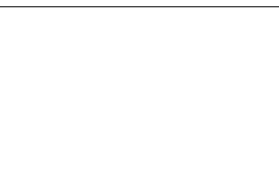 } & & & total & & \\
\hline & & & 630 & & \\
\hline & & & total & & \\
\hline & & & $100.00 \%$ & & \\
\hline
\end{tabular}

TABLE 2: The number and percentage of classroom-based observations for each of the three Sounds of Intent framework segments (Reactive, Proactive, Interactive) for 68 participants in the 5 Year 1 project schools 


\begin{tabular}{|c|c|c|c|c|c|c|c|c|c|c|c|c|c|c|c|}
\hline \multirow{4}{*}{$\begin{array}{l}\text { male }(n=41) \\
\text { female }(n=32)\end{array}$} & \multicolumn{5}{|c|}{ Reactive } & \multicolumn{5}{|c|}{ Proactive } & \multicolumn{5}{|c|}{ Interactive } \\
\hline & R1 & R2 & R3 & $\begin{array}{l}\mathrm{R} \\
4\end{array}$ & $\begin{array}{l}\mathrm{R} \\
5\end{array}$ & $\mathrm{P} 1$ & $\mathrm{P} 2$ & P3 & P4 & $\begin{array}{l}P \\
5\end{array}$ & I1 & I2 & $\mathrm{I} 3$ & $\begin{array}{l}\text { I } \\
4\end{array}$ & I5 \\
\hline & 18 & 27 & 59 & 9 & 3 & 14 & 39 & 46 & 12 & 1 & 29 & 58 & 18 & 7 & 0 \\
\hline & 19 & 25 & 47 & 9 & 1 & 11 & 32 & 41 & 11 & 1 & 21 & 45 & 24 & 2 & \\
\hline
\end{tabular}

TABLE 3: Numbers of observations within each Sounds of Intent framework segment and level by sex 


\begin{tabular}{|c|cccc|cccc|c|}
\hline Child & & Week 1 & & total & & Wk10 & & total & \\
$\mathbf{1}$ & $\boldsymbol{R}$ & $\boldsymbol{P}$ & $\boldsymbol{I}$ & score & $R$ & $P$ & $I$ & score & change \\
$\mathbf{2}$ & 3 & 3 & 3 & 9 & 3 & 3 & 2 & 8 & -1 \\
$\mathbf{3}$ & 2 & 2 & 1 & 5 & 2 & 2 & 1 & 5 & 0 \\
$\mathbf{4}$ & 1 & 2 & 1 & 4 & 3 & 3 & 2 & 8 & 4 \\
$\mathbf{5}$ & 3 & 3 & 2 & 8 & 3 & 4 & 3 & 10 & 2 \\
$\mathbf{6}$ & 3 & 3 & 2 & 8 & 3 & 3 & 3 & 9 & 1 \\
7 & 2 & 2 & 2 & 7 & 3 & 3 & 2 & 8 & 1 \\
\end{tabular}

TABLE 4: Longitudinal data on the observed musical behaviour of seven children in one school over a ten-week period. Framework levels (1-5) have been summed within the two comparison weeks (1 and 10 ) in order to generate a notion of observed 'change' during this period 